In the conditions I have described, the psychological traumas as a result of injury vary markedly, but the common element is that emotional factors outweigh cognitive or intellectual factors. The role of those involved in rehabilitation $\frac{\pi}{8}$ is to instil in the mind of the sportsman a realistic appreciation of the prognosis of the injury and thereby inhibit the? development or persistence of counter-productive emotions. As with the injury-prone athlete, the coach, the doctor and $\Rightarrow$ the physiotherapist should attempt to understand the individual rather than considering and treating an injury per se. In $?$ the more extreme cases, it would be an obvious advantage to the injured sportsman if all those with a vested interest in his complete recovery cooperated and pooled information in order to make the treatment phase more effective. At the $\frac{\bar{\sigma}}{\bar{N}}$ least, this will be to the long-term benefit of the reckless and the over-cautious sportsman.

\title{
REFERENCES
}

Bender, J. A., Renzaglia, G. A. and Kaplan, H. M. 1971. In Encyclopedia of sports science and medicine. (L. A. Larson, Ed.). Collier-Macmillan, New York.

Dollard, J. and Miller, N. E. 1950. Personality and psychotherapy. McGraw-Hill, New York,

Eysenck, H. J. 1957. The dynamics of anxiety and hysteria. Routledge and Kegan Paul, London.

Eysenck, H. J. 1963. Experiments with drugs. Pergamon, New York.

Eysenck, H. J. 1967. The biological basis of personality. C. C. Thomas, Springfield, Illinois.

Lynn, R. and Eysenck, H. J. 1961. Tolerance for pain, extraversion and neuroticism. Perceptual and Motor Skills 12: $161-162$.

Reilly, T. 1975. An ergonomic evaluation of occupational stress in professional football. Unpublished Doctoral Thesis, Liverpool Polytechnic.

Sanderson, F. H. 1977. The psychology of the injury-prone athlete. Brit.Journ.Sports Med. 11: 56-57.

***

\section{A PRACTICAL VIEW OF SOCCER INJURIES}

\author{
W. H. G. WILKINSON, AMBIM, DMS \\ Physical Education Department, Liverpool Polytechnic
}

\section{INTRODUCTION}

Risk is inherent in playing soccer. This may be attributable to sources extrinsic or intrinsic to the player. In general the 을 greater the reward, the greater is the risk a player is prepared to accept. Risk taking is an essential ingredient in sport $D$ and the physical injuries sustained in playing games is taken to be a facet of the psychology of sport (Browne and 0 Weightman, 1975). The goalkeeper is directly involved in play to a greater extent than any individual outfield player $\bar{N}$ (Reilly and Thomas, 1976) and as he enacts an essentially different role is more exposed to hazards. In general players 5 are vulnerable at a number of specific sites.

\section{SITES OF VULNERABILITY}

\section{The head}

Players are coached to make contact with the ball in heading at the frontal hairline fringe. A misjudgment against a powerfully driven kick can produce intra-cranial damage. Heading such drives with feet firmly anchored to the ground rather than off it can aggravate the resultant shock to the skull and spinal column.

Injury is frequently caused by heads clashing during heading duels. A player who is challenged on his blind side may $\stackrel{\mathbb{D}}{\stackrel{2}{2}}$ be unaware of his immediate contestant and unprepared for the consequent clash. A defender challenging from behind 
may incur severe facial injuries if his opponent's head is jerked backwards into his face in the attempt to head the ball goalwards. Fractures of facial bones and skin abrasions on bony prominences represent typical damage sustained.

Players sometimes guard against head clashes by using their arms and hands. Some players consistently employ their elbows illegally in a manner that causes painful injuries to the opponent's head and neck.

The head and neck may be severely damaged in falling. Goalkeepers are particularly prone in diving to save or at the feet of an inrushing forward. A number of severe head and neck injuries have been documented in goalkeepers.

\section{Upper body and upper limbs}

Injuries to the upper body, hands and arms can occur from falling awkwardly. Injuries to the elbow, clavicle and shoulder joint are incurred frequently in this way. The goalkeeper is especially prone to damage to the bones of the hand and wrist. The severity can be affected by the firmness of the playing surface.

One foul to be especially disapproved of is "making a back". This occurs when an opponent crouches in the path of a player leaping to head the ball, who consequently rotates over the crouched offender and lands heavily upside down. Injuries to the hand, arm or shoulder, and sometimes to the head and back, can result.

\section{The legs}

The legs account for $65 \%$ of soccer injuries and $50 \%$ of leg injuries are cuts and bruises. The most critical areas are the knee and ankle joints (Thomas and Reilly, 1975).

Kicking and lunging entail ballistic components in their execution and can lead to pulled muscles in the hamstring and adductor groups. Soccer players are particularly susceptible to groin strains. These involve the tendons of the rectus femoris, sartorius and ilio-psoas muscles.

Cartilage tears, patellar bursae strains, synovitis, quadriceps tendon injuries and torn ligaments are typical of the many injuries to the knee. Buckling at the knees on landing can lead to torn cruciate ligaments. Haematomae may develop when the quadriceps suffer heavy impact stresses.

The ankle joint is obviously injury prone from its weight-bearing role. Sprained ankles, torn ligaments, chipped malleoli, fractured tibia and fibula, Potts fracture, ruptured achilles tendon are typical liabilities. Reckless tackling often produces stressful contacts with the bones and tissues of the foot and ankle joints.

\section{CAUSAL ELEMENTS IN SOCCER INJURIES}

\section{Extrinsic factors}

(i) environmental conditions - the nature of the pitch surface and prevailing weather. These determine choice of appropriate boot stud.

(ii) footwear - design of suitable boots involves criteria of fit, comfort, protection and grip.

(iii) protective equipment - lightweight but robust shin pads are used to protect the lower leg, invariably at the individual's discretion. Protection embraces the employment of elastic or non-elastic strapping of suspect areas, especially the ankle joint.

\section{Intrinsic factors}

(i) fitness - should be specific to positional requirements and behavioural demands of play (Thomas, 1977). Fitness entails warm-up as short-term preparation as well as fitness training for longer-term preparedness.

(ii) match behaviour - requires turning, accelerating, decelerating, and running off the ball as well as leaping, kicking, tackling, landing and running at varying velocity with the ball. Physical contact can range from permissible tackles to senseless and dangerous fouls in contesting possession.

(iii) psychological factors - operate largely via the rewards and punishments associated with team success or failure, as these influence the degree to which a player will submit himself to physical danger. Other considerations are his motivational level, his security of selection and the impingement of the attendance and communication media. 


\title{
REFERENCES
}

Browne, R. C. and Weightman, D. 1975. The psychology of injuries of sport. Proceedings of FEPSAC Conference (Edinburgh), 84-88.

Reilly, T. and Thomas, V. 1976. A motion analysis of work rate in different positional roles in professional football match-play. Journal of Human Movement Studies 2: 87-97.

Thomas, V. and Reilly, T. 1975. The relationship between anxiety variables and injuries in top class soccer. Proceedings of FEPSAC Conference (Edinburgh), 213-222.

Thomas, V. 1977. Fitness within sports. Brit.Journ.Sports Med. 11: 46-49.

***

SOME OBSERVATIONS ON WEIGHT-TRAINING*

\author{
T. REILLY, B.A., Dip.P.E., M.Sc., Ph.D. \\ Physical Education Department, Liverpool Polytechnic
}

*This material was presented as a demonsträtion in an indoor gymnasium.

\section{INTRODUCTION}

Weight-lifting is a heavy resistance weight-bearing action, demanding high explosive power and the ability to hold great loads momentarily under control. Maximal efforts are employed against extreme resistances. It is at these intensities that stresses on the articuloskeletal system are greatest. Correct techniques must be employed to minimise strain at body sites of greatest vulnerability - the knee, back and wrist.

The knee is vulnerable especially at initiation of the lift before the quadriceps contract forcefully. The back experiences high strain levels, the force on a lumbo-sacral disc exceeding $1000 \mathrm{~kg}$ in the investigations of Morris et al (1961). The intra-abdominal pressures induced alleviate the load on the spine to an extent. Frequently the annular fibrosis ligaments are strained. At the wrist deterioration may occur due to hyperextension associated with repetitive lifting and holding weights overhead.

Breathing must not be suspended during the moment of extreme exertion. With the breath held and the epiglottis closed, the chest is compressed and intrathoracic pressure rises. The Valsalva manoeuvre operates, resulting in a reduced venous return to the heart and consequent rapid drop in blood pressure with possible loss of consciousness.

\section{CONVENTIONAL WEIGHT-TRAINING EXERCISES}

From a battery of lifts recognised by the British Amateur Weightlifters Association some have been adopted over the last two decades in the training of athletes. Mostly the lifts have been modified to comply with individual requirements. Attendant risks can be demonstrated in a sample of typical exercises.

\section{Arm and shoulder work}

1. Bench press - particularly employed by rugby forwards, swimmers and weight-throwers. Two spotters should be used for safety and the bar should not be taken in too high near the throat. The grip must be sufficiently wide as not to jeopardise security, since $\mathbf{4 0} \mathrm{kg}$ can lacerate the facial bones from half a metre's fall. A chest full of air should provide a rigid base from which the weight can be pushed vertically. The performer exhales as the weight ascends and inhales during its descent.

The athlete may concentrate on eccentric contractions in lowering the load, the barbell being lifted for him by assistants. This overcomes the training limitations of performing only uni-directional work and allows heavier loads to be handled. 